\title{
Effectiveness of using SOKARY Mobile Application on the compliance of patients with Type II diabetes: A quasi-experimental study
}

\author{
EHSAN A. YAHIA ${ }^{1}$, MAGDA M. BAYOUMI ${ }^{2,3}$ \\ ${ }^{1}$ Lecturer, Medical-Surgical Nursing Department, Faculty of Nursing, Cairo University \\ ${ }^{2}$ Lecturer, Medical-Surgical Nursing Department, Faculty of Nursing, Beni-Suef University. \\ ${ }^{3}$ Assistant professor, Nursing Department, College of Health and Sport Sciences, University of Bahrain. \\ Correspondence to Dr. Magda Bayoumi, Email: mbayoumi@nursing.bsu.edu.eg
}

\begin{abstract}
Mobile health applications are an easy, friendly access method for enhancing patient's compliance and overall health status. This study aimed to evaluate the effectiveness of using mobile health applications on patients' compliance. A Quasi-experimental design was used with a purposeful sample of 150 subjects who have been diagnosed with type II diabetes were recruited. SOKARY android mobile application diabetes App was selected mobile health application in Arabic interface included many features as recording blood glucose level, nutrition and physical activity with medication reminders and healthy lifestyle advice notifications. The findings showed that the effectiveness of post-using the Mobile App on patient's compliance is statistically significant $52.64+5.1,(p=0.000)$. Obviously, the improvement is statistically significant as recognized in lowering the level of $\mathrm{HbA1c}(p<0.029)$ and BMI $(p<0.006)$ and increasing level of activity $(p<0.002)$ and overall patient's compliance $(p<0.004)$.

In conclusion, the results reported significant improvement in patients' compliance and highly recommended to utilize such mobile health applications among patients to prevent the complications of Type II diabetes.

Keywords:SOKARY Mobile Application, type II diabetes, patient's compliance, HbA1c, level of activity, BMI.
\end{abstract}

\section{INTRODUCTION}

Diabetes mellitus is a heterogeneous group of disorders characterized by hyperglycemia due to an absolute or relative deficit in insulin production or action. The chronic hyperglycemia of diabetes mellitus is associated with endorgan damage, dysfunction, and failure, including the retina, kidney, nervous system, heart, and blood vessels. The International Diabetes Federation (IDF) estimated an overall prevalence of diabetes mellitus to be 425 million and predicted a rise to 629 million by $2045^{1}$. Meanwhile, in 2013, the IDF has determined the ninth leading country in Egypt around the world, and the prevalence of diabetes Type II around was $15.6 \%$ among adults with ages ranged from 20 to 79 years old 2 .

Previous studies' findings reported that patients with diabetes have a knowledge deficit about the disease process, and noncompliance and non-adherence to management remain, which lead to an increase in the prevalence of morbidity, mortality, and burden in the health care system. Thereby, those patients need self-care programs as an effective coping strategy ${ }^{3}$.

Identification of patient's needs and self-care activities are considering a part of the nursing role to teach, encourage and guide to change the patient's attitude and behaviors toward the importance of self-care to cope with chronic disease ${ }^{4}$. Interestingly, Self-care theories as Orem's Self Care Model provides principles of planning and implementing self-care, while Orem believed that self-care is the ability of a person to take of his/herself based on perceived direct care, and comprehensive educational support as a key role of nurse's role in management plan ${ }^{5,6}$.

Basically, the patients with chronic disease as diabetes need to be cooperative in all disease processes and treatment plans as well as self-care activities. Self-care plays an important part in the management plan to control the disease progression and prevent complications as selfmonitoring of blood glucose, following diet, activity, and treatment remain ${ }^{7,8}$.

A recent study recommended that utilization of welldesigned mobile application(s) for supporting the patient with diabetes in self-care, likewise applicable mobile features can provide patients a wide range of measures as medication adherence, blood sugar level, knowledge of diabetic diet, and all information that required for selfmanagement for controlling and improving patient's quality of life ${ }^{9}$.

The Global Observatory for eHealth (GOe) of the World Health Organization (WHO) defines mHealth or mobile health as "medical and public health practice supported by mobile devices, such as mobile phones, patient monitoring devices, Personal Digital Assistants (PDAs), and other wireless devices". While new wireless technologies were being developed, new mobile devices were being created. In this way, PDAs, tablets, and smartphones appeared on the market ${ }^{10}$.

Self-monitoring tools and apps are growing faster than more traditional telemedicine interventions because of the ubiquity of smartphones and the minimal development cost of health-related apps in providing flexible, scalable, mobile, and interoperable platforms. mHealth also promises greater patient engagement, given the technology's near-instant and always-on functionality, and continual use for multiple tasks. Consequently, this concept is critical to the behavior change required for improved patient outcomes ${ }^{11}$.

The aim of the study is to evaluate the effectiveness of using mobile health applications on patients' compliance levels.

Research Question: What is the effectiveness of using mobile health applications on the compliance level of patients with Type II diabetes in Egypt? 


\section{METHODS}

Quasi-experimental was used as a research design.

Participants and sampling: A purposeful sample of 150 subjects who have been diagnosed with type II diabetes were recruited from the out-patient diabetic clinic at Kasr Al-Aini university hospital (from August to December/ 2019) to fulfill the aim of the current study with the following inclusion criteria.

-Be familiar with the use of mobile health applications.

- Has type-2 diabetes diagnosis by an endocrinologist for more than one year,

-Own a smartphone with an android operating system.

-Able to use the internet either through a Wi-Fi network andlor mobile data.

\section{Data Collection:}

Section I: Patient's demographic characteristics: Included (Age, Sex, Place of Residence, Marital Status, Occupation, level of education).

Section II: Medical-related data of patients: consisted of (Body mass index (BMI, HA1c, Comorbidity, Associated complications, and Family History of DM, treatment of Diabetes). Moreover, the assessment of BMI, $\mathrm{HbA1c}$, and Level of activity, Those items were measured as baseline data then 3 months post-intervention

Section III: Patient's compliance Questionnaire: Included 14 Questions (4 questions about diet control, 2 about exercise, 2 about insulin treatment, 5 about selfmonitoring blood glucose and general management, and 1 about diabetes education) (each question was rated on a 4 point Likert scale ( $1=$ Doing very well all the time and $4=$ Doing never) with higher scores indicating the poor level of compliance ${ }^{12}$.

Section IV: Android SOKARY mobile application: diabetes App was selected as an example of mobile health application as it has the advantage of Arabic interface, free use it allows users to record their blood glucose level, nutrition, and physical activity, then provide the user with statistics for those readings. Other features as receiving notifications about medication reminders and healthy lifestyle advice (Figure1).

Data Collection Procedure:

Pre-Intervention Phase: The Ethical approval has been obtained from an authorized administrative board, then the investigators started to arrange a face to face interviews with each participant for 30-40 minutes to collect the formal consent, explain the purpose of the study, Medical-related data of patients, and Patient's compliance was collected, meanwhile, the mobile application was uploaded on their smartphones to be applicable in the Intervention phase. Intervention Phase: All participants were using the SOKARY mobile application for consecutive 3 months and recorded their blood glucose level, nutrition, and physical activity level. Moreover, they received notifications about medication reminders and healthy lifestyle advice.

Post Intervention: The investigators arranged face-to-face interviews post 3 months duration after using the SOKARY mobile application and reassess the BMI, HbA1c, Level of activity, and patient's compliance.
Ethical Considerations: Formal letters were issued from the investigators to the Medical Director of an out-patient clinic at Kasr Al-Aini university hospital of the study settings and approval was obtained on the request so it was signed and stamped from the hospital and from the Ethical Committee of the university (ClinicalTrials.gov Identifier: NCT04843592). The researcher met the patients and explained the aim and the process of the study. Patients' written consent was obtained. Complete confidentiality of any obtained information was ensured. The researcher has also assured the administration that the conduction of the study will not affect the work in the study settings. The

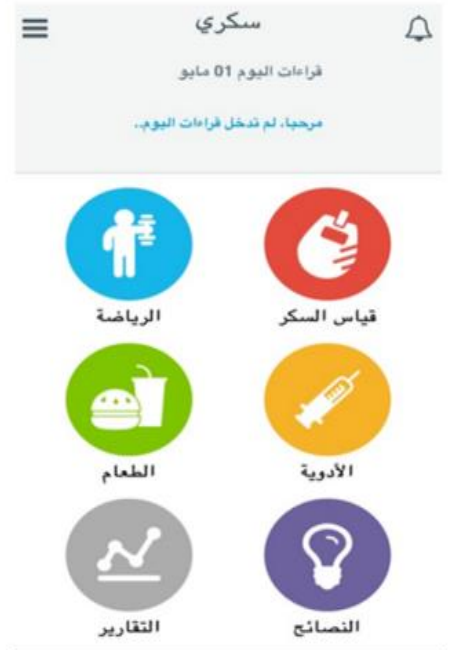

Figure 1: Android SOKARY mobile application

results of the study will be provided to the hospitals' authorities to maximize their benefits.

Data analysis: Data entry was done using SPSS 24.0 statistical software packages. Data were presented using descriptive statistics in the form of frequencies and percentages for qualitative variables, and means and standard deviations for quantitative variables. Quantitative continuous data were compared using Student t-test in case of comparisons between two groups. Paired t-test was used for pre-post comparisons of the same patients. Along with the descriptive statistics, the non-parametric Wilcoxon Signed Ranks Test (Z) was used to determine the relationship between the multiple variables, and Statistical significance was considered at $p$-value $<0.05$.

\section{RESULTS}

The socio-demographic characteristics of patients in the study sample are described in figure 2 . Most of the patients' age ranged between 40 and 60 years (93.3\%) with a mean $\pm S D 40.3 \pm 10.7$ years. Sex distribution was almost equal, with slightly more males (58\%). Education was mostly secondary $(55.0 \%)$ or university $(25 \%)$ levels. More than three-fourths of the patients were married $(73.3 \%)$ and working $(72 \%)$. As for their residence, the figure shows that almost of the patients were from urban dwellings. (80\%). 
Figure 2: Patient's Demographic Characteristics Distribution

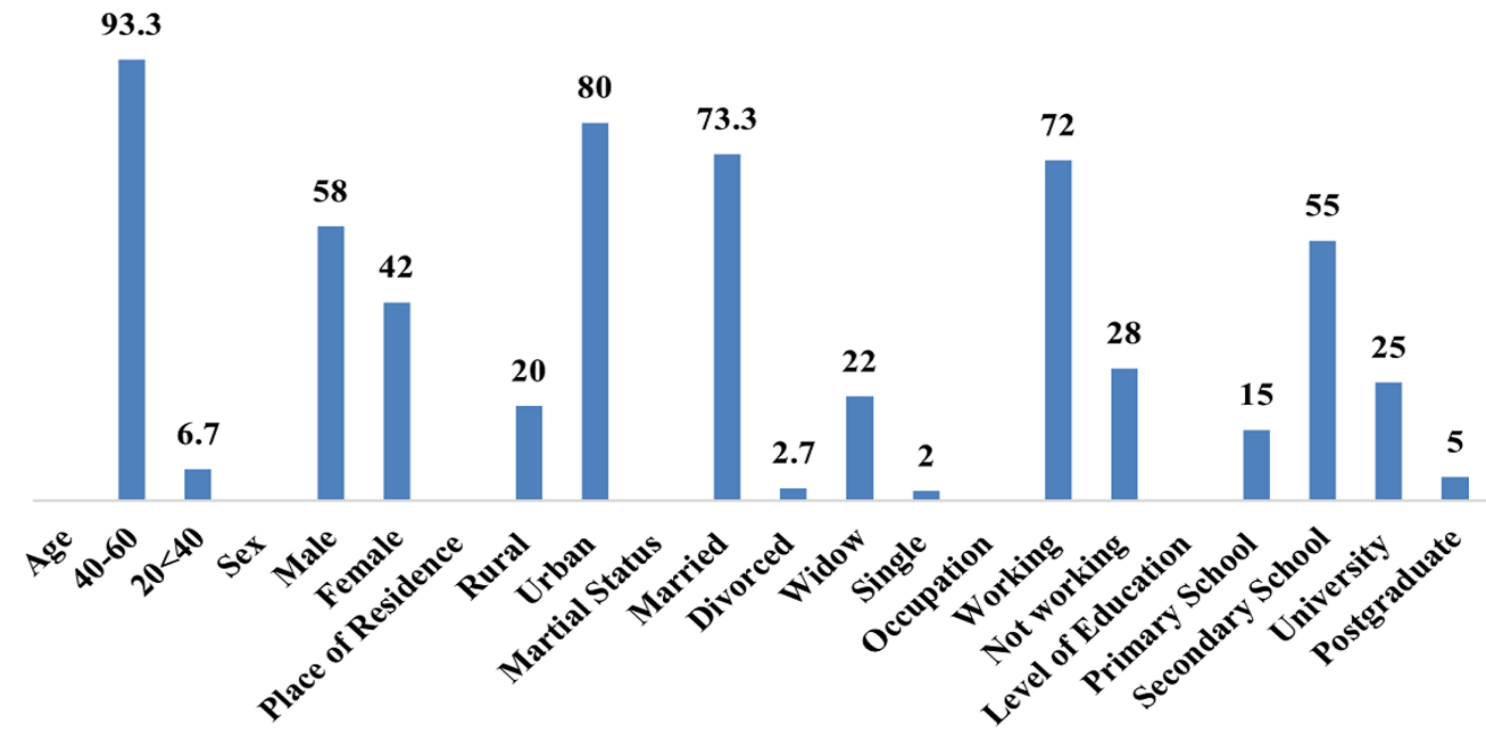

Table 1: Medical-related data of patients $(n=150)$

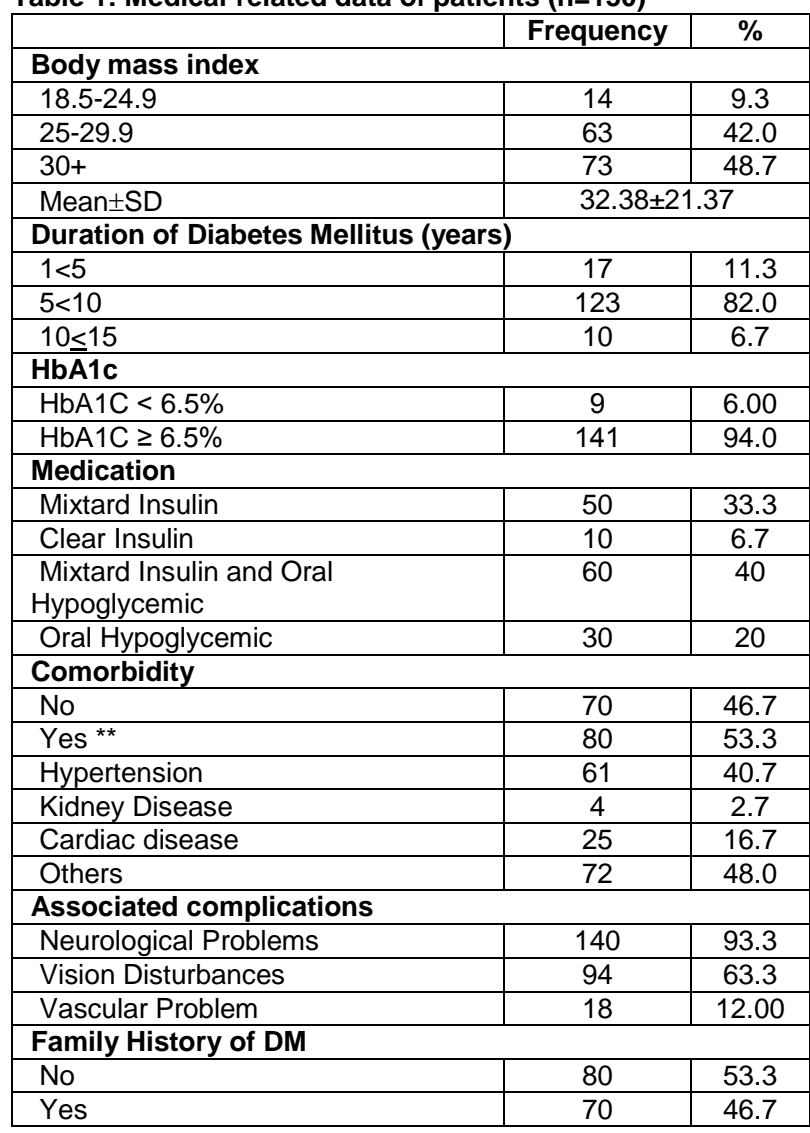

Table 1 illustrates the medical-related data of patients in the study sample, as the table shows that almost half of the study sample were categorized as either overweight or obese ( $42 \%, 48.7 \%$ respectively), and more than the threefourth $(82 \%)$ of the study sample were diagnosed of diabetes mellitus for duration 5 to less than 10 years with (94\%) uncontrolled blood glucose levels $(\mathrm{HbA1c})$ treated by a variety of Insulin and Oral hypoglycemic medication. Moreover, half of the study sample had comorbid diseases (53.3\%) as Hypertension (40.7\%) and had a family history of diabetes (53.3\%).

Table 2 describes the effectiveness of pre-post using of Mobile App on patient's compliance as assessed among patients in the study sample. It points to statistically significant increases in the patient's compliance post using of mobile application $52.64+5.1,(p=0.000)$.

Table 2: Correlation between Pre-Post using of Mobile App on patient's Compliance $(n=150)$

\begin{tabular}{|c|c|c|c|}
\hline Item & Mean (SD) & $Z^{\text {Wil }}$ & p-value \\
\hline Pre-Intervention & $19.00(6.39)$ & & \\
\hline Post-Intervention & $52.64(5.99)$ & -10.80 & $0.000^{\star *}$ \\
\hline
\end{tabular}

The relation between post-3 months of using mobile health application and $\mathrm{HbA} 1 \mathrm{c}, \mathrm{BMI}$, and activity level are displayed in table 3. As the table shows, obviously, the improvement is statistically significant as recognized in lowering the level of $\mathrm{HbA} 1 \mathrm{c}(\mathrm{p}<0.029)$ and BMI $(p<0.006)$ and increasing level of activity $(p<0.002)$ and overall patient's compliance $(p<0.004)$.

Table 3: Correlation between mobile health application use, HbA1c, BMI \& activity level after 3 months $(n=150)$

\begin{tabular}{|l|c|c|}
\hline Item & $\mathrm{t}$ & $\mathrm{p}$-value \\
\hline Mobile App use \& HbA1c & 2.698 & $0.029^{*}$ \\
\hline Mobile App use \& BMI & 9.951 & $0.006^{*}$ \\
\hline Mobile App use \& Activity level & 6.097 & $0.002^{*}$ \\
\hline $\begin{array}{l}\text { Mobile app use \& patient compliance } \\
\text { score }\end{array}$ & 8.342 & $0.004^{*}$ \\
\hline
\end{tabular}

$\left(^{*}\right)$ Statistically significant at $p<0.05$ 


\section{DISCUSSION}

Today's advanced technology is creating an easy, faster rhythm environment, indeed patient with chronic disease as diabetes can use it to enhance their overall health status by quick and frequent monitoring of relevant parameters that lead to clinical decision making and outcomes.

Many studies have shown an association between using mobile apps and the improvement of patients with diabetes mellites and the motivation to modify their lifestyle ${ }^{13-15}$.

The foregoing present study finding was concerning the effect of SOKARY Mobile Application on patient's compliance is in agreement with Adu et al, 2019 who have presented empirical support for the effectiveness of the utility of smartphone app for built based on patient's needs to support self-management of a patient with diabetes ${ }^{9}$.

In congruence with the present study findings, Bonoto et al (2017) have investigated the effectiveness of using diabetic apps to maintain the HbA1c level under control and improving patient's self-care and self-confidence to cope with diabetes ${ }^{16}$. Moreover, and in line with the present study findings, Sharma et al (2019) have described the effectiveness of mobile health interventions to improve physical activity level, and adherence to medical regimen, the results have demonstrated the efficacy of using mHealth technology to improve patient's health behavior and overall health outcomes ${ }^{17}$. Furthermore, smartphone applications facilitate self-care management to achieve the highest level of patient involvement in the intervention plan and successfully improve health outcomes ${ }^{18}$.

A recent study was done by Tassone et al (2020) who have emphasized the importance of utilizing and developing mobile apps with comprehensive content, monitoring software, and the potential to exchange data ${ }^{19}$. Interestingly, the implementation of Orem's nursing theory on a patient with Type II Diabetes is provided great guidelines for self-care programs to improve patient's quality of life4. Mobile health applications are a friendly access method for enhancing patient compliance as it is easy to access and available worldwide. While it is necessary for using such mobile apps for mutual benefit for the patient and health care providers by constant monitoring for overall health status and intern may help to reduce or prevent the complication ${ }^{20}$. Whereas assessment of patient's needs and challenges for self-care should be considered $^{21}$.

According to Adu et al (2018), who have reported that there isn't enough data in the literature about the effectiveness of implementing a diabetic mobile App on the patients self-management and compliance which is guided by linking the data with a health care provider for a better decision-making process to improve the quality of life for patients with diabetes, thereby conducting such study will help in documentation of vital information which highlighted the importance of using e.Health mobile application with chronic disease as Diabetes ${ }^{22}$.

\section{CONCLUSION}

The current research revealed significant improvement in diabetic patient compliance as well as physiological parameters such as $\mathrm{HbA1c}$, Body Mass Index, and activity level. In conclusion, Type 2 diabetes is a widespread disease that can be improved by a healthy lifestyle and patient compliance. The present study investigated the use of mobile health applications to enhance patient's compliance and the results showed significant improvement in the physiological parameters that recommend the use of mobile health applications among patients with diabetes to increase the patients' alertness in order to prevent complications and consequences of Type II diabetes which causes a huge burden on the patient financially, physically, and psychologically. In addition to reducing the cost burden on the health care system in Egypt.

Limitations of the study: Internet disconnection was reported by $5 \%$ of the participants for few days ranged between one day to 7 days, therefore they recorded all missed data manually to cover the missed days.

Funding: No funding sources

Conflict of interest: None declared

\section{REFERENCE}

1. International Diabetes Federation. IDF diabetes atlas, 8 ed. Brussels:International Diabetes Federation;2017. https://diabetesatlas.org/upload/resources/previous/files/8/IDF _DA_8e-EN-final.pdf.

2. International Diabetes Federation. Diabetes Atlas. $6^{\text {th }}$ ed.https://www.idf.org/sites/default/files/EN_6E_Atlas_Full_ $0 . p d f ; 2013$.

3. Godarzi M, Ebrahimzadeh A, Rabi A R, SaidipoorB, Asghari $M$, J. A. Examining the relationship between knowledge, attitude and Performance With self-efficacy in type 2 diabetic patients in city of Karaj. Iran J Diabetes Lipid Disord 2011; 11(3):269-81.

4. Borji M, Otaghi M, Kazembeigi S. The Impact of Orem's SelfCare Model on the Quality of Life In Patients With Type II Diabetes. Biomed Pharmacol J 2017;10(1).

5. Hemmati $M$, Hashemlo $L$, Khalkhali $H$. The effect of implementing orem's self-care model on the self-esteem of elderlies resident of nursing home in Urmia. Medical-Surgical Nurs J 2012; 1(1):18-23.

6. Meleis Al. Theoretical nursing: Development and progress: Lippincott Williams \& Wilkins.; 2011.

7. Lin CC, Anderson RM, Hagerty BM, Lee BO. Diabetes self management experience: a focus group study of Taiwanese patients with type 2 diabetes. Journal of clinical nursing 2008; 17(5a):34-42.

8. Tan MY, Magarey J. Self-care practices of Malaysian adults with diabetes and suboptimal glycaemic control. Patient education and counseling 2008; 72(2):252-67.

9. Adu MD, Malabu UH, Malau-Aduli AE, Malau-Aduli BS. Mobile application intervention to promote self-management in insulin-requiring type 1 and type 2 diabetes individuals: protocol for a mixed methods study and non-blinded randomized controlled trial. Diabetes Metab Syndr Obes 2019; 24;12:789-800.

10. Martínez-Pérez $B$, de la Torre-Díez I, López-Coronado M. Mobile health applications for the most prevalent conditions by the World Health Organization: review and analysis. J Med Internet Res. 2013; 14;15(6):e120.

11. Sama PR, Eapen ZJ, Weinfurt KP, Shah BR, Schulman KA. An Evaluation of Mobile Health Application Tools. JMIR Mhealth Uhealth 2014;2(2):e19.

12. Park OJ: The effect of social support on compliance with sick role behaviors in diabetic patients. J Nurs Acad Soc 1988;18(3):281-288

13. Torbjørnsen A, Jenum AK, Smastuen MC, et al. A low- 
intensity mobile health intervention with and without health counseling for persons with type 2 diabetes, part 1: baseline and short-term results from a randomized controlled trial in the Norwegian part of Renewing Health. Jmir Mhealth Uhealth 2014;2(4).

14. Goyal S, Morita P, Lewis GF, Yu C, Seto E, Cefazzo JA. The systematic design of a behavioural mobile health application for the self-management of type 2 diabetes. Can J Diabetes 2016;40 (1):95-104. doi:10.1016/j.jcjd.2015.06.007 64.

15. Whitehead L, Seaton $P$. The effectiveness of selfmanagement mobile phone and tablet apps in long-term condition management: a systematic review. J Med Internet Res. 2016;18(5).

16. Bonoto $B C$, de Araújo VE, Godói IP, de Lemos LL, Godman B, Bennie M, Diniz LM, Junior AA. Efficacy of Mobile Apps to Support the Care of Patients With Diabetes Mellitus: A Systematic Review and Meta-Analysis of Randomized Controlled Trials. JMIR Mhealth Uhealth 2017; 1;5(3):e4.

17. Sharma A, Mentz RJ, Granger BB, Heitner JF, Cooper LB, Banerjee D, Green CL, Majumdar MD, Eapen Z, Hudson L, Felker GM. Utilizing mobile technologies to improve physical activity and medication adherence in patients with heart failure and diabetes mellitus: Rationale and design of the TARGET-HF-DM Trial. Am Heart J. 2019;211:22-33.
18. Jeffrey $T$, Bagala B, Creighton M, Leavey A, Nicholls T, Wood S, Longman C, Barker J, Pit J. Mobile phone applications and their use in the self-management of Type 2 Diabetes Mellitus: a qualitative study among app users and non-app users. Diabetology \& Metabolic Syndrome Diabetol Metab Syndr 2019; (11): 84-90.

19. Tassone C, Keshavjee K, Paglialonga A, Moreira N, Pinto J, Quintana Y. Evaluation of mobile apps for treatment of patients at risk of developing gestational diabetes. Health Informatics J. 2020 ;26(3):1983-1994.

20. Riley WT, Rivera DE, Atienza AA, Nilsen W, Allison SM, Mermelstein R. Health behavior models in the age of mobile interventions: are our theories up to the task? Transl Behav Med 2011 Mar;1(1):53-71.

21. Arsand E, Tatara N, Østengen G, Hartvigsen G. Mobile phone-based self-management tools for type 2 diabetes: the few touch application. J Diabetes Sci Technol 2010 ;4(2):328336.

22. Adu MD, Malabu UH, Callander EJ, Malau-Aduli AE, MalauAduli BS. Considerations for the Development of Mobile Phone Apps to Support Diabetes Self-Management: Systematic Review. JMIR Mhealth Uhealth. 2018; 6(6):e10115. 